\title{
Sólo en el pueblo confiamos: la estructura moral del discurso político radical de los pobladores en el Partido Igualdad
}

\author{
"Only in the people we trust": The moral structure of the Chilean urban poor's \\ radical political discourse in the Partido Igualdad
}

\author{
Nicolás Angelcos*, Claudia Jordana* y Cristóbal Sandoval ${ }^{* * *}$
}

Resumen: En el presente artículo, se analiza la estructura del discurso político radical de los pobladores chilenos, a través del caso del Partido Igualdad. La hipótesis que orienta este artículo es que el discurso que vehiculiza el Partido tiene una lógica populista centrada en el significante pueblo y elementos antielitistas. Si bien esta estructura coincide con la literatura contemporánea acerca del populismo, el significante pueblo estaría limitado por otros dos significantes: el "sufrimiento compartido" y la "dignidad", lo que restringe sus posibilidades de articulación.

Palabras clave: Partido Igualdad, discurso político, pobladores, populismo, dignidad, sufrimiento compartido.

\begin{abstract}
In the present article, the structure of the radical political discourse of the Chilean squatters is analyzed through the case of the Partido Igualdad. The hypothesis that guides the article is that the discourse of the party has a populist logic centered on the signifier "the people" and anti-elitist elements. Although this structure coincides with contemporary literature about populism, the signifier "the people" would be limited by two other signifiers: "shared suffering" and "dignity", which restricts their possibilities of articulation.
\end{abstract}

Keywords: Partido Igualdad, political discourse, Chileans urban poor, populism, dignity, shared suffering.

Recibido: 1 junio 2018 Aceptado: 18 julio 2018

\footnotetext{
* Chileno, autor principal. Doctor en sociología, École des Hautes Études en Sciences Sociales. Profesor asistente Universidad Andres Bello y Universidad de Chile, Investigador adjunto del Centro de Estudios de Conflicto y Cohesión Social (COES). Proyecto Fondecyt Postdoctorado "Luchas por el derecho a la ciudad en el Gran Santiago: significados críticos contra la desigualdad social y política en contextos de proximidad residencial" (n'3160542), 2015-2018; Fondap “Centro de Estudios de Conflicto y Cohesión Social” (n¹5130009), 2013-2018. nicolas.angelcos@unab.cl

* Chilena, coautora. Doctora en sociología, École des Hautes Études en Sciences Sociales, Centre Maurice Halbwachs (ENS-EHESS-CNRS). claudiajordanacontreras@gmail.com

*** Chileno, coautor. Cientista Político, Universidad Diego Portales. Estudiante de Magister en Ideología y análisis de discurso, University of Essex. cs17360@essex.ac.uk
} 
El estudio del comportamiento de los pobladores ha sido históricamente uno de los pilares fundamentales en la investigación sobre la acción política de las clases populares en América Latina y en Chile ${ }^{1}$. Tal como señala Bryan Roberts ${ }^{2}$, los debates acerca de la marginalidad en los años sesenta estaban estrechamente relacionados con los actores políticos de la época. Por una parte, hay quienes sostienen que los partidos fueron importantes agentes de mediación entre las organizaciones de pobladores- sus demandasy el Estado ${ }^{3}$ mientras que otros destacan su capacidad de conducción y orientación política $^{4}$. En la vereda opuesta, contrario a este diagnóstico, hay quienes señalan la autonomía del movimiento de pobladores respecto a los partidos, en particular por el privilegio de la acción directa y la débil formalización de su política5.

Auyero $^{6}$ destaca que- siguiendo a Portes y Perlman- los tópicos de la anomia y el radicalismo han dominado el debate sobre las prácticas políticas de los pobres en Latinoamérica. Por una parte, inspirados por los trabajos de Oscar Lewis7, la teoría de la marginalidad- asociada a la política de promoción popular de la Democracia Cristianadestacaba la desorganización individual, familiar y comunitaria que caracterizaba a los habitantes de sectores populares, causa de su falta de participación social y política en la sociedad $^{8}$. Por otra parte, los investigadores asociados al CIDU, especialmente Manuel Castells ${ }^{9}$, destacaban el carácter político de la acción de los pobladores, sobre todo a través de las tomas de terreno, interrogando sobre sus distintas formas de articulación con la lucha de clases y su rol dentro de la transición hacia el socialismo.

\footnotetext{
1 Dentro de la literatura historiográfica, destacan los trabajos de Manuel Loyola, Los pobladores de Santiago, 1952-1964, Santiago, Ediciones Universidad Católica Raúl Silva Henríquez, 2006; Mario Garcés, Tomando su sitio: el movimiento de pobladores de Santiago, 1957-1970, Santiago, LOM, 2002; Gabriel Salazar, La violencia politica popular en las "Grandes Alamedas". La violencia en Chile 1947-1987 (Una perspectiva histórico popular), Santiago, LOM, 1987; Vicente Espinoza, Para una historia de los pobres de la ciudad, Santiago, Ediciones Sur, 1988. Entre los trabajos historiográficos recientes, destacan Mónica Iglesias, Rompiendo el cerco: El movimiento de pobladores contra la dictadura, Santiago, Radio Universidad de Chile, 2011; Edward Murphy, For a proper home: housing rights in the margins of urban Chile, 1960-2010, Pittsburgh, University of Pittsburgh Press, 2015; Marcia Cury, El protagonismo popular chileno. Experiencias de clase y movimientos sociales en la construcción del socialismo (19641973), Santiago, LOM, 2018.

2 Mercedes González de la Rocha, Janice Perlman, Helen Safa, Elizabeth Jelin, Bryan R. Roberts y Peter M., "Ward, From the Marginality of the 1960s to the "New Poverty" of today: A LARR Research Forum", Latin Research Review, vol. 31, n¹, 2004, pp.183-203.

3 Vicente Espinoza, op. cit.; "Historia social de la acción colectiva urbana: los pobladores de Santiago, 19571987", Revista EURE, vol. 24, n72, 1998; Manuel Loyola, op. cit.

4 Manuel Castells, "Movimientos de pobladores y lucha de clases en Chile", Revista EURE - Revista De Estudios Urbano Regionales, vol. 3, n7, 1973, pp. 9-35; Boris Cofré, “El movimiento de pobladores en el Gran Santiago: las tomas de sitios y organizaciones en los campamentos. 1970-1973", Tiempo histórico, n², 2011, pp.133-157; Alexis Cortés, “El movimiento de pobladores chilenos y la población La Victoria: ejemplaridad, movimientos sociales y el derecho a la ciudad". Revista EURE, vol.40, n¹19, 2014, pp. 58-78.

5 Gabriel Salazar, op. cit.; Mónica Iglesias, "La construcción teórica de los movimientos sociales en Chile: el movimiento de pobladores, entre la sociología y la historia social”, Revista Austral de Ciencias Sociales, n³0, 2016, pp.145-160.

6 Javier Auyero, Pacientes del Estado, Buenos Aires, Eudeba, 2013.

7 Oscar Lewis, Los hijos de Sánchez, México, Fondo de Cultura Económica, [1961] 2012.

8 Roger Vekemans y Ramón Venegas, “Marginalidad y promoción popular”, Revista Mensaje, 149, 1966.

${ }_{9}^{9}$ Manuel Castells, op.cit.
} 
El golpe de Estado en 1973, aun cuando no frenó completamente las movilizaciones de los pobladores ${ }^{10}$, implicó una anulación del debate precedente hasta comienzos de los años ochenta. En el marco de la profunda crisis económica que vivía el país y las crecientes protestas contra la dictadura, resurgieron los estudios sobre el comportamiento social y político de los pobladores: por un lado, se destacaban las prácticas económicas a través de las cuales los sectores populares organizaban la sobrevivencia11; y, por otro lado, se analizaba su capacidad para trascender la segregación socioeconómica que los afectaba y proyectarse políticamente tras la recuperación de la democracia ${ }^{12}$. Desde esta perspectiva, tal como señalaba Rodrigo Baño13, la articulación entre lo social y lo político parecía ser el "dilema clave" del movimiento popular.

Por otro lado, a fines de los años ochenta, distintos investigadores, adscritos a la ONG Sur, fueron instalando progresivamente la pregunta por el comportamiento violento de los pobladores, especialmente de los hombres jóvenes, en las protestas contra la dictadura. Recuperando en parte las orientaciones generales de la teoría de la marginalidad, se destacó el carácter delincuencial del comportamiento popular, lo que los distanciaba cada vez más de la consideración legítima de la política ${ }^{14}$.

La forma en que se dio la transición política a la democracia, basada en la negociación entre una coalición de partidos políticos de centro-izquierda y la junta militar, excluyó, entre otros, a los pobladores como actor político. Pese a que, tal como señala Patricio Aylwin ${ }^{15}$ en su primera cuenta pública, el problema de la pobreza fue una prioridad de su gobierno, las estrategias para combatirla no van a considerar más a los pobladores como sujetos. A partir del conjunto de políticas públicas que podemos englobar bajo el rótulo de "estrategias de lucha contra la pobreza", los pobladores van a ser considerados exclusivamente como beneficiarios.

Ante este nuevo escenario, la pregunta por el comportamiento político de los sectores populares no desaparecerá completamente, pero, tal como sostenía la teoría de la marginalidad en los años sesenta, la "resignación, abulia, apatía"16serán sus actitudes características. En este sentido, la pregunta por la falta de participación política, cuyo indicador será sobre todo la progresiva abstención electoral de los jóvenes pobres17, y por

\footnotetext{
10 Alison Bruey, "Limitless land and the redefinition of rights: popular mobilisation and the limits of neoliberalism in Chile, 1973-1985", Journal of Latin American Studies, vol. 44, 2012, pp.523-552.

11 Luis Razeto, Economía popular de solidaridad. Identidad y proyecto en una visión integradora, Santiago de Chile, PET, 1986; Clarisa Hardy, Organizarse para vivir. Pobreza urbana y organización popular, Santiago de Chile, PET, 1987.

12 Guillermo Campero, Entre la sobrevivencia y la acción politica: las organizaciones de pobladores en Santiago, Santiago de Chile, Estudios ILET, 1987; Alain Touraine, "La centralidad de los marginales", Proposiciones, Marginalidad, movimientos sociales y democracia, vol. 14, Santiago de Chile, 1987, pp. 214-224.

13 Rodrigo Baño, Lo social y lo político. Un dilema clave del movimiento popular, Santiago de Chile, FLACSO, 1984.

14 Eugenio Tironi, “El fantasma de los pobladores”, Estudios sociológicos, vol.4, n¹2, sept-dic, 1986, pp. 391-397; François Dubet, "Las conductas marginales de los jóvenes pobladores”, Proposiciones, Marginalidad, movimientos sociales y democracia, n¹4, Santiago de Chile, agosto 1987, pp. 94-100.

15 Aylwin, Discurso 21 de mayo, 1990.

16 Vekemans, op. cit.

17 Sebastián Madrid, “¿Políticos de ayer, apáticos de hoy? Generaciones, juventud y política en Chile”, Claudia Fuentes y Andrés Villar, Voto ciudadano. Debate sobre la inscripción electoral, Santiago de Chile, FLACSO, pp. 4584.
} 
la violencia delictual ${ }^{18}$, orientarán las investigaciones sobre el mundo popular durante las décadas siguientes.

En una dirección similar, parafraseando el célebre libro de Javier Auyero'19, el estudio sobre la política de los pobres se enfocará principalmente en el análisis de las relaciones clientelares que sostienen los distintos partidos políticos- incluyendo ahora a los partidos de derecha- con las distintas organizaciones populares ${ }^{20}$. Tanto en el caso de la falta de participación política como en el clientelismo, se trata de un comportamiento político de "baja calidad" que contrasta con el "radicalismo" que orientaba buena parte de las investigaciones en los años setenta. De esta forma, desde los años noventa en adelante, la gran mayoría de los estudios realizados desde una perspectiva crítica sobre el comportamiento de los sectores populares se ha centrado en señalar los mecanismos mediante los cuales el Estado domina a los pobres ${ }^{21}$, explicando así, lo que Edward Murphy22 llama la "domesticación de la periferia".

Sin desconocer la importante desmovilización de los pobladores tras la recuperación de la democracia, lo cierto es que, en los últimos años, hemos visto emerger nuevamente a distintas organizaciones, vinculadas fundamentalmente con la lucha por el derecho a la vivienda y la ciudad, que disputan la representación de los sectores populares a través de un discurso político radical, cuyo momento de aparición pública fue la campaña presidencial de la dirigenta del Andha Chile a Luchar Democrático ${ }^{23}$ Roxana Miranda el año 2013. A través de esta campaña, se hizo visible el partido político Igualdad24, resultado de la articulación entre distintas organizaciones sociales y políticas, principalmente de pobladores, que, enmarcado en una retórica anticapitalista, pone en el centro del discurso al pueblo.

\footnotetext{
18 Azun Candina, "Seguridad ciudadana y sociedad en Chile contemporáneo. Los delincuentes, las políticas y los sentidos de una sociedad", Revista de estudios históricos, vol. 2, n¹, agosto 2005.

19 Javier Auyero, La política de los pobres, Buenos Aires, Manantial, 2012.

${ }^{20}$ Emmanuelle Barozet, "Elementos explicativos de la votación de los sectores populares en Iquique: lógica y eficiencia de las redes clientelares", Política, n43, 2004, pp. 205-251; Emmanuelle Bazoret, "La compra de votos en Chile o cómo se coopta a los sectores populares", Contribuciones científicas y tecnológicas, pp.10-15; Evelyn Arriagada, "Clientelismo político y participación local. El rol de los dirigentes sociales en la articulación entre autoridades y ciudadanos en Santiago de Chile”, Revista Polis, n³6, 2013, pp. 15-38; Ani $\square$ bal Pe $\square$ rez C., ¿UDI popular? Los campamentos y el respaldo electoral-popular de derecha. El caso de Virginia Reginato en Vin $\square$ a del Mar (2008-2013), Izquierdas, n²1, octubre 2014, pp. 1-30.

21 Philip Oxhorn, "Where did all the protesters go?: Popular mobilization and the transition to democraty in Chile", Latin American Perspectives, vol. 21, n³, verano 1994, pp. 49-68; Julia Paley, Marketing democracy: Power and Social Movements in Post-Dictatorship Chile, Berkeley, University California Press, 2001; Clara Han, Life in debt: Times of Care and Violence in Neoliberal Chile, Berkeley, University California Press, 2012; Ş. İlgü Özler, "The Concertación and Homelessness in Chile: Market-based Housing Policies and Limited Popular Participation", Latin American Perspectives, vol. 39, n4, 2012, pp. 53-70; Carter M. Koppelman, "Deepening Demobilization: The State's Transformation of Civil Society in the Poblaciones of Santiago, Chile", Latin American Perspectives, vol. $44, n^{\circ} 3,2017$, pp. $46-63$.

22Edward Murphy, op. cit.

23 Agrupación que reúne a deudores habitacionales en su lucha por la condonación de sus deudas. Ver: http://andha.cl.

24 Ver https:// partidoigualdad.cl.
} 
Más allá de sostener que esta aparición pública representa una reemergencia del movimiento de pobladores 25 , en este artículo quisiéramos proponer un marco analítico para identificar los componentes principales del discurso político radical que ha movilizado el Partido Igualdad 26 y que, a nuestro juicio, forman parte del repertorio discursivo de los sectores populares 27.

La hipótesis que orienta este artículo es que el discurso político radical que vehiculiza el Partido Igualdad tiene una estructura moral- a partir de la cual critica al capitalismo y busca su superación- centrada en el significante pueblo. Esta estructura coincidiría con la descripción que hace la literatura especializada del "discurso populista", donde el concepto pueblo operaría como un "significante vacío" que permitiría establecer una frontera antagónica con la élite o bloque de poder (oligarquía) ${ }^{28}$. En el caso del discurso político radical de los pobladores, la apertura del significante pueblo estaría limitada por el significante "sufrimiento compartido", asociándolo a la subjetividad del poblador. Finalmente, la "dignidad" se posiciona como un significante central para caracterizar al pueblo, tanto en su condición de subordinado como de protagonista.

Para demostrar nuestra hipótesis, se analizó el discurso político del partido Igualdad, a partir del análisis propuesto por Laclau en "La razón populista"29, utilizando los conceptos de articulación, lógica de la equivalencia, significante vacío y frontera antagónica. Se tomaron como fuentes distintas entrevistas realizadas a dirigentes del partido y de los movimientos que lo componen. Dichas entrevistas fueron efectuadas entre los años 2010 y 2013 en el marco de la tesis doctoral "La construcción de lo político en las nuevas generaciones de pobladores" defendida por uno de los autores el año 2015 en la École des Hautes Études en Sciences Sociales de París. Paralelamente, en el marco del proyecto Fondecyt Postdoctorado no3160542, se revisaron los diferentes números del diario "Voces por la Igualdad", herramienta de difusión del partido entre los años 2010 y 2013.

Nuestro artículo se estructura en tres partes: en primer lugar, se describe a grandes rasgos el movimiento de pobladores en la actualidad y cómo, dentro de su despliegue, se

\footnotetext{
${ }^{25}$ En otro artículo, analizamos la reemergencia del movimiento de pobladores a partir de la toma de Peñalolén. Nicolás Angelcos y Miguel Pérez, "De la “Desaparición” a la Reemergencia: Continuidades y Rupturas del Movimiento de Pobladores en Chile", Latin American Research Review, vol. 52, n¹, 2017, pp. 94-109.

26 El discurso movilizado por Igualdad es representativo de distintas organizaciones de pobladores que reivindican el derecho a la vivienda y la reconstrucción de un movimiento popular, por ejemplo, el Movimiento de Pobladores Ukamau, el Movimiento por la Dignidad o el mismo Andha Chile a Luchar Democrático quienes, ya no estando en Igualdad, movilizan el mismo discurso político radical.

27 Tal como destacan Dubet et al., dentro de las lógicas de acción del movimiento de pobladores en los años ochenta, se encuentra la lógica de "ruptura revolucionaria" que, aun siendo minoritaria, está muy presente en el discurso de los jóvenes pobladores. François Dubet, Eugenio Tironi, Vicente Espinoza y Eduardo Valenzuela, Pobladores. Luchas sociales y democracia en Chile, Santiago de Chile, Ediciones Universidad Alberto Hurtado, 2016.

28 En la literatura contemporánea, se ha destacado la dificultad de definir el fenómeno populista, como lo señala Claudio Riveros, “El proceso populista: un aporte teórico al debate del fenómeno", Izquierdas, n³8, febrero 2018, pp. 61-88.

En este artículo se adopta un enfoque político-discursivo incorporando algunos elementos del enfoque ideacional propuesto por Cas Mudde, principalmente el carácter maniqueo de la relación antagónica que existe entre el pueblo y la elite en el discurso populista.

29 Ernesto Laclau, La Razón Populista, Buenos Aires, FCE, 2005.
} 
crea el Partido Igualdad; en segundo lugar, se analiza la estructura de este discurso, identificando aquellos elementos que comparte con el populismo; y en tercer lugar, se destacan las especificidades del discurso de los pobladores a partir de las nociones de "sufrimiento compartido" y de "dignidad".

\section{El movimiento de pobladores y el Partido Igualdad}

Como señalamos, si bien en los últimos tiempos se ha producido una desmovilización importante de los sectores populares, esto no ha significado la desaparición del movimiento de pobladores. Tal como han señalado Angelcos y Pérez ${ }^{30}$, el movimiento de pobladores ha mostrado indicios de rearticulación desde los años 1990, inicialmente con la Toma Esperanza Andina en 1992, y sobre todo en 1999, con la célebre Toma de Peñalolén, cuando 1700 familias ocuparon ilegalmente 24 hectáreas de terreno en la comuna de Peñalolén. Ambas tomas representan una continuidad con el repertorio de acción tradicional del movimiento de pobladores.

Por otra parte, en la década pasada, la ciudad de Santiago presenció el nacimiento de numerosos comités de allegados, que en 2010 dieron vida a la Federación Nacional de Pobladores (FENAPO), una instancia de coordinación nacional para luchar contra las políticas exclusionarias de la vivienda. Estas organizaciones de pobladores, en continuidad con la identidad histórica del movimiento, están compuestas principalmente por pobladores "sin techo" y su demanda específica sigue siendo la vivienda.

Sin embargo, si bien la demanda por vivienda ha sido aquella por la cual inicialmente se han movilizado los pobladores, al interior de la organización esta demanda ha sido utilizada como un vehículo para reivindicaciones de mayor alcance, como la apropiación del territorio y la integración a la ciudad. En la medida en que las políticas de vivienda impulsadas desde la transformación neoliberal en adelante han tendido a confinar a los pobres a la periferia de la ciudad, las movilizaciones contemporáneas de familias sin casa se han estructurado en torno a la reivindicación del derecho a permanecer en las comunas donde se han socializado. De esta forma, se ha ido instalando, al interior del movimiento de pobladores, un discurso que va más allá del acceso a la vivienda, y apunta al derecho a la ciudad ${ }^{31}$.

Al revisar distintas declaraciones de la Federación Nacional de Pobladores o cualquier otro documento programático de los comités de allegados mayormente movilizados, resulta relevante apuntar que el "derecho a la ciudad" ha emergido con fuerza como una reivindicación que acompaña al reclamo por la vida digna y la demanda territorial.

\footnotetext{
30 Angelcos y Pérez, op. cit.

31 Miguel Pérez, "A new poblador is being born". Housing Struggles in a Gentrified Area of Santiago", Latin American Perspectives, Vol 44, n³, 2016, pp. 28-45; Nicolás Angelcos y Maria Luisa Méndez, "Struggles against territorial disqualification. Mobilization for dignified housing and defense of heritage in Santiago", Latin American Perspectives, vol. 44, n³, 2017, pp.100-112; Angelcos y Pérez, 2017, op. cit.
} 
Como se ha argumentado en otro artículo 32 , esto ha significado que las movilizaciones de los pobladores no sólo representen una lucha social, contra el desplazamiento de los pobres hacia la periferia urbana, sino también una lucha política, contra el sistema de dominación que orienta tales políticas. La lucha por la vivienda es el espacio a través del cual los pobladores han movilizado una serie de acciones y críticas dirigidas contra el modelo de desarrollo, y contra el desprecio ${ }^{33}$ del Estado a la capacidad de agencia de los pobladores.

Es así como a partir del año 2010, distintas organizaciones de pobladores, entre ellas, Andha Chile a Luchar Democrático, el Movimiento Pueblo Sin Techo y el Movimiento de Pobladores en Lucha, decidieron crear el Partido Igualdad, como una herramienta política para la representación de las organizaciones que reivindican el derecho a la vivienda y la reconstrucción de un movimiento popular. A diferencia de períodos anteriores, en que los partidos actuaban como mediadores o conductores de la movilización, en el caso de Igualdad, han sido las mismas organizaciones quienes han decidido representarse a través un partido ${ }^{34}$. A este respecto, una dirigente nos comenta:

El partido Igualdad (nace de) la necesidad de copar esos espacios para poder golpear la mesa po' (...) poder informar y poder sacar infraestructura $y$ poder sacar financiamiento de los espacios institucionales, ¿cachai? pero no tan solo pa' eso, sino también para en algún momento poder cambiar las políticas, o sea, es decir el auto gobernarse, no estar siempre criticando el discurso, no estar siempre criticando la política en este caso habitacional, sino que también en algún momento tener una, pero como tenis una si lo únicos que son capaces de tener política habitacional son aquellos que llegan al poder, al gobierno. Entonces ¿es importante llegar al gobierno? Sí po, es importante porque efectivamente desde el gobierno podríamos generar condiciones para poder elaborar políticas públicas de vivienda, que permitieran un mayor y mejor acceso a los pobladores ${ }^{35}$

En concordancia con el diagnóstico y los objetivos de las distintas organizaciones de pobladores, desde el Partido Igualdad se ha planteado un discurso político radical, que promueve una transformación profunda de la sociedad en múltiples ámbitos. En primer lugar, de lo que se trata es de derribar el modelo neoliberal y capitalista, y sus consecuencias en materia de vivienda, pero también en lo que respecta a la salud, la educación, la preservación del medio ambiente, etc.; y, en segundo lugar, de generar una política en la que "el pueblo mande", es decir, donde el poder le sea arrebatado a los ricos y poderosos, a la clase política tradicional, y devuelto al pueblo.

\footnotetext{
32 Nicolás Angelcos, "Movimiento de pobladores. Lucha social y política en el Chile contemporáneo", Revista Educação em perspectiva, vol. 7, n², 2016, pp. 324-345.

33 Axel Honneth, La lutte pour la reconnaissance: grammaire morale des conflits sociaux, Paris, Cerf, 2010.

34 Pese a los bajos resultados obtenidos en las elecciones, la formación del Partido ha tenido efectos significativos en la dinámica del movimiento. Por ejemplo, a partir del debate en torno a la candidatura de Roxana Miranda a la presidencia y luego su evaluación, el mismo ANDHA Chile a Luchar Democrático decide dejar el partido y construir uno propio.

35 Entrevista Denis, militante Igualdad.
} 
De esta forma, el discurso desarrollado es abiertamente contrario a la manera como se han llevado las políticas sociales y económicas en los últimos cuarenta años. Hay una crítica generalizada al modelo neoliberal heredado de la dictadura, y a las profundas desigualdades e injusticias que este conlleva.

El Partido Igualdad se presenta a sí mismo como una alternativa frente a la política tradicional, ya sea de la derecha o de la Concertación ${ }^{36}$, como un actor con propuestas realmente nuevas, con la idea de cambiar de paradigma o de modelo de sociedad. Las expresiones "construir una sociedad mejor", "la sociedad soñada" o "refundar la sociedad", abundan en sus discursos, dando cuenta de esta intencionalidad. En ese sentido, Igualdad se declara como un partido no sólo anti-neoliberal, sino también anticapitalista.

Ahora bien, pese a que el partido se defina como anti-capitalista, esto no supone la adscripción inmediata a un proyecto alternativo como el socialismo ${ }^{37}$, como habría podido suceder en otra época. Por el contrario, lo que observamos son más bien un conjunto de demandas que abarcan desde la renacionalización de los recursos naturales, hasta la creación de una nueva Constitución a través de una Asamblea Constituyente, pasando por la educación gratuita y de calidad y el fin de las AFP.

Por otra parte, el Partido Igualdad también ha desarrollado una fuerte crítica hacia el sistema político actual y su carácter elitista y excluyente, promoviendo la necesidad de devolver la política a los ciudadanos y, en particular, al pueblo, para que este decida su mejor forma de gobernarse. Una de las principales consignas del Partido “iQue el pueblo mande!", expresa nítidamente esta reivindicación.

En la Declaración del Acta de la Igualdad, publicada en el primer número de la revista Voces por la Igualdad, podemos ver expresadas estas reivindicaciones:

DECLARAMOS: Chile necesita profundas transformaciones sociales políticas y económicas, que jamás vendrán desde los poderosos y sus partidos. Esos cambios reales sólo vendrán desde los Pueblos organizados y en lucha, impulsando la construcción de un gobierno que encabece estas transformaciones y propicie una nueva institucionalidad. Por ello los Pueblos vamos a crear nuevas formas de Vida y de gobierno con una nueva institucionalidad a través de la Constitución Política para Chile: la Constitución de la Igualdad ${ }^{38}$

De esta forma, el discurso del Partido Igualdad asume un tono marcadamente fundacional. De lo que se trata no es de acceder a mejores beneficios por parte del Estado, sino de constituirse en tanto sujetos políticos, disputar el poder en el plano de la política institucional y llevar adelante transformaciones profundas en cuanto al modelo de desarrollo. Ahora bien, como veremos en las siguientes páginas, la radicalidad del

\footnotetext{
36 Concertación de Partidos por la Democracia: coalición de partidos de centro-izquierda que gobernó en Chile desde el retorno a la democracia en 1990 hasta el año 2010.

${ }^{37}$ En distintas entrevistas, algunos dirigentes nos señalaron su adscripción explícita al socialismo, sin embargo, más allá de las motivaciones personales, en el discurso de Igualdad, el significante "socialismo" tiene una posición periférica.

38 Acta de la Igualdad, Revista Voces por la Igualdad, nº1, 2010, p.2
} 
discurso de Igualdad no sólo está dada por la existencia de estas reivindicaciones de carácter radical, sino también por la forma en que se estructura su discurso.

\section{La lógica populista del discurso político radical del Partido Igualdad}

El discurso político radical del Partido Igualdad tiene como eje central la denuncia del capitalismo y de sus consecuencias nefastas en la vida social. Desde Igualdad, se plantea la necesidad de garantizar lo que ellos consideran el principal derecho de las personas: el derecho a gobernar y a autogobernarse, arrebatándole el poder a los ricos y poderosos. Se trata de un discurso centrado en torno al significante "pueblo", que desarrolla a partir de ahí una representación antagónica del mundo social, en la cual cobra una particular relevancia el elemento moral. Efectivamente, no sólo las críticas y las demandas son formuladas en clave moral, sino también la descripción del sujeto político "pueblo" y su oposición a la elite.

En este sentido, la estructura del discurso político radical de los pobladores coincide en gran medida con la descripción que hace la literatura especializada del "discurso populista", entendido dentro del enfoque político-discursivo e ideacional, desarrollado por Ernesto Laclau ${ }^{39}$ y Cas Mudde 40 respectivamente. En este sentido, es posible definir al populismo como una lógica o morfología discursiva que construye lo político a partir la división de la sociedad en dos campos, el pueblo puro (los de abajo) y la elite corrupta. Además, esta lógica comprende la política como la realización de la voluntad general del pueblo. En palabras de Laclau, "sin construcción y totalización de una nueva voluntad colectiva global, no hay populismo" 41 . De esta forma, este artículo toma distancia de los estudios sobre populismo en el contexto chileno en el cual han predominado enfoques que lo comprenden asociado al personalismo y la demagogia, un mal manejo de la economía (subordinándola a la política) o a un estilo político ligado al clientelismo y a liderazgos locales ${ }^{42}$. Al posicionarnos dentro del enfoque políticodiscursivo, enfatizamos el carácter principalmente formalista del populismo en cuanto a un modo de construcción de lo político ${ }^{43}$. En el presente apartado, veremos cómo los

39 Laclau, 2005, op. cit.

40 Cas Mudde, "The Populist Zeitgeist", Government and Opposition, vol. 39, n4, 2004, pp. 541-563. Este enfoque está inspirado en en el análisis morfológico de las ideologías de Michael Freeden. Michael Freeden, Ideologies and Political Theory: A Conceptual Approach, Oxford, Oxford University Press, 1996.

41 Ernesto Laclau, "Lógicas de la Construcción Política e Identidades Populares", José Luis Coraggio y JeanLouis Laville (coord.), Reinventar la Izquierda en el Siglo XXI: Hacia un Dialogo Norte-Sur, Los Polvorines, Universidad Nacional de General Sarmiento, 2014, p.253.

42 Alexis Cortés y Alejandro Pelfini, “El populismo en Chile: ¿tan lejos o tan cerca?”, Izquierdas, n³2, marzo 2017, pp. 58-78.

43 Dentro del enfoque político-discursivo, reconocemos la relación que existe con el enfoque ideacional propuesto por Cas Mudde el cual comprende al populismo como una ideología o sistema de creencias definida por la existencia de alguna noción de un pueblo puro en oposición a una elite malvada y la primacía de la voluntad general como fuente de legitimidad política. No obstante, siguiendo a De Cleen, Glynos y Mondon, el enfoque asumido en este artículo comprende al populismo como un patrón articulatorio, no así un sistema de creencias, el cual puede articular una serie de elementos ideológicos (de izquierda o derecha) desde una 
distintos elementos que desarrolla el discurso de Igualdad se articulan en torno a una lógica populista.

Como indicamos, uno de los elementos centrales del discurso político radical de los pobladores es estructurarse a partir del significante pueblo. Una de las principales consignas defendidas por el Partido Igualdad es "que el pueblo mande" y las referencias al "pueblo" abundan en sus discursos y declaraciones. Esta idea le permite cuestionar los modelos tradicionales de representación política, en la medida que el pueblo aparece como lo irrepresentable:

Y lo decimos claro: no queremos más gobiernos que dicen representar al pueblo. Queremos que el pueblo mande y se mande, que gobierne y se autogobierne ${ }^{44}$

Venimos desde los movimientos sociales en lucha a hablarle a nuestro pueblo sobre su máximo derecho: su derecho a gobernar ${ }^{45}$

No es un gran partido ideológico doctrinario, hay puntos muy básicos $\mathrm{pa}^{\prime}$ trabajar en conjunto, los principales puntos son: es la idea fundamental digamos de decir en Chile no hay ninguna solución de fondo, real pa' nuestro pueblo mientras no gobierne nuestro pueblo porque mientras gobiernen los ricos no hay ninguna solución real pa' la gente, las únicas soluciones del fondo, reales, transformaciones de verdad que puedan producirse digamos en dignidad, justicia social, igualdad pa' la gente es cuando nuestro pueblo lo mande ${ }^{46}$.

Como podemos observar en estos fragmentos, el punto central a partir del cual se estructura el discurso de Igualdad es la necesidad del pueblo de autogobernarse. Esta necesidad obedecería a la imposibilidad de alcanzar conquistas para el mundo popular en un marco de representación definido por los intereses de los ricos.

Esta posición central que adquiere el pueblo al interior de la estructura discursiva de Igualdad es reforzada por un conjunto de demandas que van dotándolo de significado, entre ellas: la educación gratuita y de calidad, el fin de las Isapres y de las AFP, el cambio de la Constitución a través de una asamblea "popular" constituyente, el respeto al medioambiente, el desarrollo sustentable, etc.

La educación gratuita, laica y de calidad para tod@s 1@s chilen@s, término al sistema de isapres y AFP por uno solidario que cubra de manera digna y calidad a tod@s, cambio al sistema electoral binominal y cambio de la constitución a través de una vía constituyente popular y de los pueblos donde el eje central sea la participación de tod@s 1@s ciudadan@s y organizaciones sociales y territoriales. Desarrollo económico sustentable y con respeto al medioambiente, desarrollo de las ciencias y las tecnologías

lógica populista. Mudde, op. cit.; Benjamin De Cleen, Jason Glynos y Aurelien Mondon, "Critical research on populism: Nine rules of engagement", Organization, Online first, pp. 1-13.

https://doi.org/10.1177/1350508418768053

${ }_{44}$ Editorial, Revista Voces por la Igualdad, ${ }^{\circ} 7$, junio 2013, p.2.

45 Editorial, Revista Voces por la Igualdad, n¹, agosto 2010, p.3.

46 Entrevista Igor, militante Igualdad. 
que sirvan de manera real al desarrollo de nuestra nación en lo económico, cultural, artístico, biológico y en el campo de las ideas. ${ }^{47}$

Se establece así, para decirlo en los términos de Laclau ${ }^{48}$, una cadena de demandas equivalentes entre sí, que permite al discurso de Igualdad producir una crítica radical al sistema de dominación que caracteriza nuestra sociedad. Efectivamente, según Laclau, la subjetividad popular, asociada a la articulación equivalencial de demandas heterogéneas, sólo es posible en la medida que exista una frontera interna antagónica que permita la articulación de demandas de manera negativa (en oposición a algo). Por ello, debe establecerse la división de lo social entre el poder y el pueblo, porque sin una construcción discursiva de un enemigo, el populismo no puede emerger. Las distintas demandas formuladas por el movimiento logran articularse en la medida en que se oponen, de manera conjunta, al capitalismo. Es a partir de ahí, efectivamente, que cobra sentido su declaración anticapitalista:

Nuestros principios son la participación democrática, horizontal y asamblearia en todas nuestras decisiones; la construcción del poder del pueblo como única fuerza transformadora; el anticapitalismo, porque el capitalismo es el origen de tanta injusticia, problemas y miseria que vive la humanidad; nunca seremos serviles ni nos aliaremos a los partidos de los ricos como son la concertación y la alianza de derecha; legalizaremos este instrumento político para llevar al pueblo chileno al gobierno y no para negociar cupos o cargos en los gobiernos de los patrones. ${ }^{49}$

Denunciamos el carácter inhumano y depredador del capitalismo que a través de los grandes capitalistas -nacionales y extranjeros - ejercen su poder controlando la economía, el gobierno, los medios de comunicación, explotando a la clase trabajadora, negando la_identidad de los pueblos originarios, depredando a la Madre tierra, dejándonos sólo migajas, consagrando su sistema de muerte por sobre la Vida. ${ }^{50}$

Como vemos, el sistema capitalista es percibido como la causa no sólo de las desigualdades socioeconómicas ("la explotación de la clase trabajadora"), sino también de la depredación de la madre tierra, de la negación de la identidad de los pueblos originarios, de la violencia contra las mujeres, los niños y las niñas, entre otros. Esta doble crítica al carácter "depredador e inhumano" del capitalismo permite desde ya identificar la crítica social con la crítica moral, elemento constante al interior del discurso de Igualdad. El sistema capitalista es criticado porque, de alguna manera, "pervierte" el conjunto de la sociedad. De esta forma, queda en evidencia cómo el discurso político del Partido Igualdad busca constituir un proyecto contra-hegemónico que modifique las condiciones de existencia de los pobladores y los desfavorecidos ${ }^{51}$.

\footnotetext{
47 Editorial, Revista Voces por la Igualdad, n4, diciembre 2012, p.2.

48 Laclau, 2005, op. cit.

49 Editorial, Revista Voces por la Igualdad, n'1, agosto 2010, p.3

50 Acta de la Igualdad, Revista Voces por la Igualdad, n¹, agosto 2010, p.2.

51 Riveros, op. cit.
} 
El elemento moral es aún más visible cuando se describen las clases sociales, "los ricos" y "los pobres", y la clase política, cómplice del gran empresariado. Se construye, de esta manera, una representación antagónica del campo social, asociada a variaciones de la distinción moral entre lo bueno/malo y lo virtuoso/vicioso, donde el "pueblo" aparece como virtuoso, y la elite como corrupta y malvada. De esta manera, el discurso de Igualdad se condice con lo señalado por Cas Mudde ${ }^{52}$ a propósito del discurso populista, según quien esta división discursiva de la sociedad en grupos homogéneos y antagonistas,

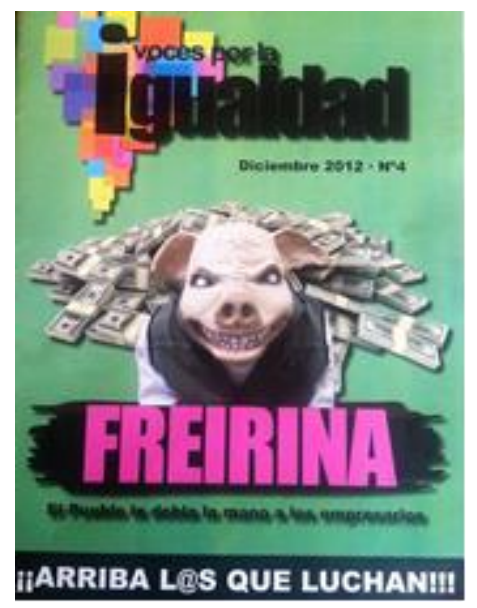
se hace en una clave moral: el antagonismo está mediado por una relación maniquea entre el pueblo y la elite.

Hoy queda más que claro que la rapiña empresarial chilena busca, por todos los medios, aprovechar el sufrimiento de cientos de miles de compatriotas para hacer sus negocios, sacar ganancias y lucrar con la desgracia ajena. El gobierno de Piñera viene a garantizar más ganancia y lucro para los ricos dueños de Chile, lo que significa más pobreza, explotación y humillación para el pueblo. Debemos impedirlo. ${ }^{53}$

Los ricos, los empresarios, aparecen retratados como malvados, egoístas, ambiciosos, incapaces de percibir la desgracia y el sufrimiento ajenos, como una verdadera "rapiña", o como "cerdos", como se observa en esta imagen de portada de la revista de Igualdad. En cambio, los pobres aparecen como buenos, solidarios, generosos, valientes y luchadores, que, a pesar del sufrimiento, la explotación y la humillación sufrida, son capaces de levantarse para defender su dignidad.

Yo creo en este proyecto porque lo componen personas honestas y luchadoras. ${ }^{54}$

La política es el espacio social donde se deciden todas las leyes que nos rigen, pero que no favorecen nunca al pobre ¿Por qué? Simple: porque las leyes las hacen los ricos. Si dejamos que esto siga así, estamos dejando en las manos de políticos corruptos y mentirosos los destinos de nuestras familias y del país. Por eso los pobres de Chile debemos tomar la política en nuestras manos. Nuestra política, que nacerá desde las poblaciones pobres de Chile, será distinta, será democrática, transparente, de lucha, participativa, y tendrá siempre el objetivo de garantizar los derechos del pueblo chileno. 55

Como vemos en estas citas, esa lectura también se lleva al plano de la política: los políticos tradicionales son corruptos, mentirosos, están aliados con el gran capital.

\footnotetext{
52 Mudde, op. cit.

53 Editorial, Revista Voces por la Igualdad, nº1, agosto 2010, p.3.

54 Revista Voces por la Igualdad, $\mathrm{n}^{\circ} 1$, agosto 2010, p.7.

55 Revista Voces por la Igualdad, n¹, agosto 2010, p.6.
} 
Interesante es la representación que se da de la Concertación, en la cual estos aparecen como traidores. Dicen representar a los pobres, a los más desfavorecidos, pero, en realidad, también están del lado de las grandes empresas. Bajo esta óptica, "los gobiernos de la Concertación" aparecen como equivalentes de "Pinochet y los economistas de Chicago". Además de compartir sus intereses económicos, no son capaces de "actuar con valentía".

¿Tú también Judas? Sabemos por qué Pinochet y los economistas de Chicago cambiaron al país. Porque echaron la culpa de la crisis de los ' 70 a la intervención del Estado en una economía que no podía adecuarse a los vientos de cambios que soplaban por el globo. Otra cosa es por qué los gobiernos de la Concertación eran (y serán) neoliberales, con o sin querer. Una cosa es que no quieran enfrentar los poderes que realmente mandan en este país, entonces no pueden controlar la "libre empresa" en manos de los Luksic, los Matta, los Paulmann. No quieren enfrentarlos porque, por un lado, son sus amigos, y son poderosos. Y por el otro, porque el éxito de la economía, el éxito que entrega los impuestos al Estado, depende de las ganancias de las empresas de esos multimillonarios. Es que ellos también creen en el goteo de los multimillonarios "hacia abajo". Después de todo, ellos también creen que la intervención del Estado en la economía no puede adecuarse al viento de cambios que soplaba por el globo. Dicen

Como vemos, el discurso político de Igualdad tiene una estructura antagónica que divide el campo social en dos: por un lado, los ricos, quienes, además de sus intereses de clase, son descritos como malvados o perversos; y, por otro lado, los pobres, caracterizados como buenos, valientes y solidarios. Esta distinción entre una élite corrupta y un pueblo virtuoso coincide, como vimos, con la descripción que hace Mudde ${ }^{57}$ del discurso populista, donde el antagonismo social es representado en términos morales. El carácter moral de esta estructura cuestiona la distinción política tradicional entre izquierda y derecha. De hecho, si bien muchos militantes se consideran de izquierda, no definen al partido en estos términos. En algunos documentos, se destaca la posición del partido "abajo y a la izquierda", no solamente "a la izquierda":

Como Partido Igualdad (...) no nos definimos como izquierda ni derecha, ni centro ni socialista, es un partido popular, una herramienta del pueblo y si hay que acercarse a alguna es de izquierda, de izquierda revolucionaria, pero el movimiento a su gente, a todo los que nos rodean no les dice a nosotros somos de izquierda y somos de este lado no, es algo que se va dando naturalmente, que se va entendiendo, se van manejando muchos conceptos de izquierda en el discurso, pero no hay una definición así como directa ${ }^{58}$

\footnotetext{
56 Revista Voces por la Igualdad, n4, agosto 2010, p.10.

57 Mudde, op. cit.

58 Entrevista a Marcela, militante Igualdad.
} 
Como se puede observar en esta cita, la definición de izquierda no está ausente en la descripción que hacen los militantes de su posición ideológica o del tipo de demandas que reivindican, sin embargo, no limita la adscripción al colectivo. En el siguiente apartado, mostraremos cómo el pueblo que busca interpelar el discurso de Igualdad no está compuesto únicamente por una articulación de demandas equivalentes expresadas en un lenguaje de derechos, sino que se estructura en torno a una experiencia particular de sufrimiento y dignidad que no puede ser mediada y que restringe sus posibilidades de articulación discursiva. Esta experiencia, característica del pueblo, se articula con la historia del movimiento de pobladores.

\section{Pueblo, sufrimiento compartido y dignidad}

Como pudimos observar en el apartado precedente, el discurso político de Igualdad tiene una lógica populista que pone en el centro al significante pueblo. En sus investigaciones recientes sobre populismo, Laclau ${ }^{59}$ destaca que el pueblo no posee un contenido particular, sino que está siempre abierto a ser llenado de forma tal que pueda articular demandas heterogéneas. En este sentido, Laclau caracteriza al pueblo como un significante vacío ${ }^{60}$ que surge de la construcción de una frontera interna antagónica con el poder.

Siguiendo esta perspectiva, queremos mostrar dos elementos que particularizan el discurso de Igualdad sobre el pueblo y que, a nuestro juicio, permiten conectarlo con las distintas lógicas de acción ${ }^{61}$ que orientan el comportamiento político de los sectores populares, específicamente a los pobladores, a saber: el sufrimiento compartido y la dignidad. En este sentido, el discurso de Igualdad tiene una estructura populista que lo articula sincrónicamente con otros discursos similares a lo largo del mundo, pero que moviliza ciertos significantes particulares que le permiten establecer una continuidad diacrónica con la experiencia política de los pobres urbanos.

\section{"No somos vulnerables sino que vulnerados" 62}

En un artículo publicado el año 2000, Marie- Christine Doran ${ }^{63}$ propone que el discurso político de los pobladores se caracteriza por una "sintaxis fusional", es decir, por la enunciación colectiva de un nosotros que cuestiona a los diferentes "discursos de

\footnotetext{
59 Laclau, 2005, op. cit

60 Siguiendo a Laclau el significante vacío emerge porque existe una imposibilidad de la significación en cuanto tal. En este sentido, el significante vacío pueblo sería un intento de significar el objeto imposible que representa la plenitud de la sociedad. De esta manera, el discurso político populista se caracteriza por el hecho de que el significante vacío pueblo opera como un punto nodal que permite articular una serie de demandas insatisfechas en oposición al poder existente. Ernesto Laclau, Emancipation(s), London, Verso, 1996.

61 Dubet et al. Destacan la existencia de cuatro lógicas de acción que orientan el comportamiento político de los pobladores: 1) la lógica reivindicativa; 2) la lógica de participación populista; 3) la lógica de defensa comunitaria; y 4) la lógica de ruptura revolucionaria. Dubet et al., op. cit.

62 Lautaro Guanca, militante Igualdad, Diario Voces de la Igualdad.

63 Marie-Christine Doran, “La palabra soberana: los pobladores chilenos frente a la política”, Versión, n¹0, octubre 2000, pp. 287-329.
} 
mediación" que buscan representarlo, ya sean los partidos políticos, la Iglesia católica u otros actores. La imposibilidad de representar el discurso de los pobladores- que destacamos en el apartado precedente- a juicio de la autora, se explicaría por la centralidad que tiene "el sufrimiento compartido" en la definición del "nosotros, los pobres" que moviliza este discurso político. En esta misma perspectiva, Dubet et al. muestran cómo, al interior de la lógica de defensa comunitaria, los pobladores se autodescriben como una comunidad moral, "como aquel que defiende la vida de todos los días, aquel que defiende al Ser Humano en su derecho a la dignidad, aquel que es una víctima inocente"64. Estos autores destacan cómo el sufrimiento es utilizado para definir al adversario, representado en los años ochenta por la dictadura y por las clases medias, estas últimas "demasiado alejadas del sufrimiento del pueblo" 65 .

En consonancia con estos argumentos, en este apartado, quisiéramos proponer que el "sufrimiento compartido" opera como una restricción discursiva que limita, en última instancia, las posibilidades de variación del discurso político de Igualdad. Esto significa que, si bien en torno a la frontera antagónica que define su discurso se articula una amplia cadena de demandas equivalentes, el sujeto colectivo (pueblo) que se construye está sobredeterminado por el significante "sufrimiento compartido".

Como veremos en la siguiente carta, Rafael Soto- dirigente de comité de allegados y ex candidato a diputado- resalta la experiencia vivida y compartida por la comunidad, que no es otra que la experiencia de la pobreza, el "hacinamiento, la enfermedad, el empleo precario y la violencia que genera este sistema para con nuestra gente".

No hablamos desde la teoría ni elaboramos nuestras propuestas desde la intelectualidad de arriba. Nuestros proyectos en materia de vivienda, salud, educación, trabajo y seguridad brotan desde el hacinamiento, la enfermedad, la desinformación, el empleo precario y la violencia que genera este sistema para con nuestra gente ${ }^{66}$

¿A quién refiere Rafael cuando habla de "nuestra gente"? La historia que relata, y a partir de la cual pretende dar cuenta de una identidad compartida, no es la historia de la sociedad chilena en su conjunto, es la historia del pueblo pobre, de los marginales, de los pobladores. Se trata de una historia de sufrimiento, de privaciones, de migración en búsqueda de una mejor vida, de represión y desprecio por parte de las élites, en fin, de una marginación y exclusión constante de la vida social y política del país.

La historia de nuestras familias no es muy distinta entre nosotros, pero sí es muy diferente a "nuestros representantes". Nuestros abuelos campesinos llegaron a Santiago entre los años 1940 y 1960 provenientes del Valle del Limarí, Monte Patria, huyendo de la pobreza que azolaba a nuestros antepasados en los campos de todo Chile con la esperanza de vida digna para sus hijos, nuestros padres, y sólo se encontraron con la indiferencia y el desprecio de la clase dominante teniendo que nutrir la ya

\footnotetext{
${ }^{64}$ Dubet et al., op. cit., p.130.

65 Ibid., p. 132.

66 Rafael Soto, “Carta abierta”, Revista Voces por la Igualdad, n 9, octubre 2013, p.3.
} 
creciente periferia pobre de la capital y de otras ciudades que sufrieron el mismo fenómeno producto del éxodo de miles de campesinos. Nuestros padres dejaron su juventud sin mucha educación y como obreros en las fábricas debieron trabajar duro para salir adelante en una sociedad la cual le negaba lo que les correspondía siendo estos erradicados y desgarradas sus familias hacia diferentes puntos de la ciudad para proveer de techo a sus hijos, quienes de ellos no tuvieron estas mínimas "oportunidades" acabaron sus vidas a la sombra del hampa para poder sobrevivir ${ }^{67}$

Como se puede apreciar en este discurso, la historia de "nuestra gente", de "nuestras familias", es la historia de los pobladores, quienes migraron del campo a mitad del siglo pasado y que hoy son erradicados "hacia diferentes puntos de la ciudad". Esta historia se construye en oposición a la de los ricos, a los poderosos, lo que abarca tanto la clase explotadora, como a la clase dirigente, "nuestros representantes" dice Rafael Soto. De hecho, estos dos grupos son percibidos como cómplices en tanto pertenecientes a una misma "clase social".

Esta caracterización del pueblo a partir de una experiencia compartida de sufrimiento es reforzada, en el diario Voces de la Igualdad, por distintos testimonios individuales que relatan, desde un enfoque centrado en lo cotidiano, diferentes aspectos en la vida de los sectores populares. Estos relatos más íntimos, que tienen que ver con las historias familiares, pero también con las decisiones personales de participar en la organización, van limitando las posibilidades de variación del discurso de los pobladores, en la medida que refieren a una subjetividad mucho más específica.

Yo vivía allegada en la casa de los suegros, en una casa atrás. Entonces llegué a la Florida con mi pareja y nos inscribimos en un Comité. No queríamos seguir en la casa de los suegros porque vivir como allegada es fome, porque uno no tiene su espacio, uno no tiene lo propio ${ }^{68}$.

Tengo historia también. Mi mamá era de la toma de la Nueva Habana y llegué acá a los cinco meses. Entonces conozco la historia de las tomas y rescato un poco la historia de mis padres. Tengo 42 años y no quiero que me quiten mis raíces ${ }^{69}$.

Desde esta perspectiva, si bien el discurso de Igualdad busca articular una pluralidad de demandas que van más allá de los pobladores (educación gratuita, No + Afp, entre otras), cuando caracteriza el tipo de subjetividad colectiva que busca movilizar para una transformación radical de la sociedad chilena, el "sufrimiento compartido" aparece como una restricción que limita el espacio de articulación política. Son solamente los sectores populares, los trabajadores, los pobres organizados, los pobladores, quienes"buenos y valientes"- serán capaces de crear "la nueva sociedad del buen vivir".

¿QUÉ ES EL PARTIDO IGUALDAD?: Somos el partido de los que decimos ¡BASTA! Somos el Partido del pan, somos el Partido de la casa,

67 Idem.

68 Jenny, Revista Voces por la Igualdad, n7, junio 2013, p.5

69 Angélica, Revista Voces por la Igualdad, n7, junio 2013, p.4 
somos el Partido del trabajo, de la salud y la educación dignas. Somos el partido de los obreros de la construcción, de la dueña de casa, de los pobladores, de los temporeros, de los empleados, de los pescadores artesanales, de los pueblos originarios. Somos el partido de las madres y los niños. Somos el partido que aspira a una nueva relación entre los humanos y su medio ambiente. Somos el partido de los trabajadores manuales e intelectuales, de los estudiantes, de las mayorías y minorías discriminadas y excluidas. Somos el partido de la tierra, el agua y el cobre. Somos el Partido del mar, el campo y la ciudad. Somos el Partido de la libertad, de la cultura la justicia social y la igualdad. Somos el partido de los buenos y valientes, somos el Partido de los seres humanos que guiados por el amor crearemos la nueva sociedad del buen vivir, Somos el Partido de la nueva Constitución. Somos el instrumento político de los que luchan, una herramienta necesaria para conquistar nuestros sueños 70

En una entrevista realizada a una dirigenta del Partido, nos destaca cómo el poblador aparece como una categoría más flexible que la del trabajador para caracterizar al pueblo:

El poblador se entiende (como) el vecino desde la niña que va a la escuela, desde su mamá, desde su papá todos ellos en conjunto forman la población, así que denominarlo como trabajador o no trabajador entonces ¿dónde queda la dueña de casa? me acuerdo que discutíamos en ese tiempo claro porque está el estudiante, el trabajador pero ¿dónde está la dueña de casa, la vecina que está todo el día en la casa? (...) nosotros somos pobladores y siempre decimos lo mismo, un político no va a venir a decirnos lo que el pueblo necesita si nosotros somos pobladores igual y ya sabemos ahora lo que tenemos que empezar a cuajar ${ }^{71}$

Como vemos, si bien el discurso de Igualdad permite articular inicialmente un conjunto de demandas heterogéneas en torno al significante vacío "pueblo", lo cierto es que dicho discurso va siendo restringido en la medida que se articula con la experiencia de vida de los pobres urbanos y, en particular, de los pobladores ${ }^{72}$. En el discurso de Nuria, el poblador es movilizado como una categoría política73 que permite articular a un conjunto de subjetividades (el vecino, el estudiante, el trabajador, la dueña de casa, la niña que va a la escuela) detrás de un nosotros que se opone a todos aquellos que no comparten las mismas necesidades (los ricos, la clase media, los políticos). Para profundizar en esta idea, en el siguiente apartado, desarrollaremos otro elemento que permite particulizar el tipo de

\footnotetext{
70 Acta de la Igualdad, Revista Voces por la Igualdad, n¹, agosto 2010, p.2

${ }^{71}$ Entrevista a Nuria, militante Igualdad.

72 Siguiendo a Laclau es posible comprender que en el discurso del Partido Igualdad existe un intento de operación hegemónica a partir de una lógica de encarnación. De esta forma, los pobladores como un grupo particular buscan encarnar la universalidad y plenitud de la comunidad. En otras palabras, los pobladores en cuanto los menos favorecidos (plebs) buscan volverse el cuerpo de todos los ciudadanos (populus). Laclau, 1996, op. cit.; Laclau, 2005, op. cit.

73 Angelcos y Pérez, op. cit.
} 
subjetividad colectiva al que hace referencia el discurso de Igualdad, a saber: el significante dignidad.

\section{"La dignidad no se mendiga, se conquista luchando"74}

Un segundo elemento característico del discurso político de los pobladores y que es movilizado en el discurso de Igualdad, para describir al pueblo, es el significante dignidad. Esta referencia a la dignidad en el discurso de los sectores populares ha sido ampliamente destacada por la literatura en ciencias sociales. En algunos casos, se ha señalado cómo las organizaciones de pobladores reivindicaban la dignidad frente a la represión y exclusión sociopolítica de la cual eran víctimas en dictadura75. En otros casos, se ha evidenciado cómo los pobres urbanos movilizan el significante dignidad para desidentificarse respecto a la discriminación y estigmatización de la cual son objeto en su vida cotidiana76. En investigaciones recientes sobre poblaciones, se ha destacado la importancia del significante dignidad para caracterizar formas de acceso al consumo ${ }^{77}$ y de recuperar la memoria respecto a luchas pasadas ${ }^{78}$. Finalmente, en investigaciones contemporáneas sobre acción colectiva, se ha relevado la reivindicación pública de la vida digna como un horizonte político del movimiento de pobladores ${ }^{79}$.

Tal como destacan Ch. Taylor 80 o R. Forst 81 , el significante dignidad ha tenido históricamente una posición central en las distintas luchas contra formas de dominación injustificadas. En este sentido, la dignidad es una forma moral de reivindicar la igualdad entre los distintos seres humanos, independientemente de su identidad o posición social específica. En el caso del discurso de Igualdad, el significante "dignidad" aparece en diferentes ocasiones, ya sea para caracterizar el horizonte al que se aspira (viviendas dignas, salud digna, etc.) o a los sujetos que reivindican ("dignidad de sus habitantes”).

El Partido Igualdad impulsará los cimientos de la nueva sociedad a través de la Constituyente Social, proceso a través del cual acompañaremos a los pueblos y trabajadores en la tarea de imaginar, diseñar e instaurar una nueva Constitución para Chile que garantice la dignidad de sus habitantes ${ }^{82}$

\footnotetext{
74 Roxana Miranda, ex militante Igualdad, Diario Voces de la Igualdad.

75 Hardy, op. cit.; Philip Oxhorn, "The popular response to an authoritarian regime: shantytown organizations since the military coup", Latin American Perspectives, vol. 18, n¹, invierno 1991, pp. 66-91; Dubet et al., op. cit.

76 Javier Martínez y Margarita Palacios, Informe sobre la decencia. La diferenciación estamental, Santiago de Chile, Ediciones Sur, 1996; Kathya Araujo, Habitar lo social: usos y abusos en la vida cotidiana en el Chile actual, Santiago de Chile, LOM, 2009.

77 Han, op. cit.

78 Murphy, op. cit.

79 Angelcos y Pérez, op. cit.; Angelcos, op. cit.; Pérez, op. cit.

80 Charles Taylor, El multiculturalismo y la "política del reconocimiento, México, D.F., Fondo de Cultura Económica, 1993.

81 Rainer Forst, Justificación y crítica, Buenos Aires, Katz, 2015.

82 Acta de la Igualdad, Revista Voces por la Igualdad, n¹, agosto 2010, p.2.
} 
A través de la reivindicación de la dignidad, asociada a distintas demandas específicas, los pobladores exigen su reconocimiento como seres humanos, condición que ha sido usurpada por los "grandes saqueadores de nuestro país".

(Roxana Miranda) se la jugará, como hasta ahora lo ha hecho, por conquistar para la mayoría explotada y abusada, condiciones para vivir con dignidad e igualdad 83

Hemos sufrido la represión y hostigamiento constante, pero alzándose el pueblo cada vez más fuerte a fin de devolverle la dignidad usurpada a una ciudad que debería brillar por contar con el principal puerto de transferencia de carga del país" Milko Caracciolo, San Antonio, la ciudad traicionada ${ }^{84}$.

Como podemos observar, además de explotada, la mayoría aparece descrita como "abusada". La denuncia del abuso es recurrente en el discurso de Igualdad. Gran parte de los problemas sociales se refieren al abuso: el abuso de los empleadores, el abuso de los poderosos, el abuso de las empresas con los consumidores, el abuso de los recursos naturales. El significante "abuso" aparece constantemente como algo que impide justamente el acceso a los derechos y, por ende, a la dignidad.

No son pocos en Buin los abusos, la corrupción, y la apatía que ha suscitado la repartija vil del poder entre las dos coaliciones tradicionales. Una de dura derecha, y la otra que pretende llenarse la boca con una supuesta "izquierda" que no es más que populismo barato ${ }^{85}$.

La ley de subcontratación, surgió por el abismante abuso que reciben los trabajadores en régimen de subcontratación y que, en la práctica, solo sirvió para naturalizar algo aberrante socialmente como la esclavitud y la trata o comercialización de las personas ${ }^{86}$

Tal como señala Kathya Araujo ${ }^{87}$ en su análisis del habitar popular, el "abuso" reemplaza la idea de "explotación" para caracterizar la experiencia de dominación de los sectores populares. La idea de abuso tiene contenida la idea del poder, la discriminación, del aprovechamiento, pero este aprovechamiento puede venir de muy distintos ámbitos. La usurpación de derechos es leída como abuso, los derechos hay que recuperarlos para recuperar la dignidad.

La dignidad se posiciona, así, como un significante central para caracterizar al pueblo. A diferencia de la posición ocupada en otros discursos populares, la dignidad no sólo es utilizada para caracterizar la situación de exclusión social que viven los sectores más pobres de la población, sino también para denunciar al sistema capitalista que niega una vida digna. Es, en este sentido, tal como presentamos en el apartado precedente, que

\footnotetext{
83 Editorial, Revista Voces por la Igualdad, n5, marzo 2013, p.2.

84 Revista Voces por la Igualdad, nº, junio 2013, p.12.

${ }^{85}$ Cristóbal Robinson Leiva, candidato por Buin, Revista Voces por la Igualdad, n³, noviembre 2012, p.4

86 Christian Riveros, secretario general del sindicato de los subcontratados de Tresmontes Lucchetti, Revista Voces por la Igualdad, $\mathrm{n}^{\circ} 7$, noviembre 2012, p.6.

87 Araujo, op. cit.
} 
el capitalismo es descrito no sólo como un sistema de explotación, sino como "depredador e inhumano". Asimismo, la dignidad no refiere solamente a una experiencia vivida, sino también a un componente que se activa en la lucha. De este modo, el significante dignidad no se moviliza únicamente para valorizar una experiencia de sufrimiento compartido, sino para caracterizar, tal como señalamos anteriormente, al pueblo “que dice ¡BASTA!” y que camina "hacia el buen vivir". En este sentido, la "dignidad" no sólo busca interpelar a la "mayoría explotada y abusada", sino a "la gente buena// solidaria, respetuosa, luchadora". En esta misma dirección, un dirigente de Igualdad nos señala cómo la dignidad no es un elemento pasivo, sino que se obtiene a través de la lucha política:

A nosotros nos gusta la marcha, yo te digo que esa weá te da dignidad porque la lucha te hace digno po'. No es el caso de someterte al poder de estos políticos, de los empresarios, la lucha te libera de toda esa weá88.

Manteniendo la oposición entre:

Mi vida digna no nace por la vivienda digna, a lo mejor por mi vida digna puedo llegar a la vivienda, entonces lo nuestro no es solamente la vivienda... nos amarra la organización, el deseo de formar una comunidad diferente ${ }^{89}$.

En síntesis, podemos observar cómo el discurso de Igualdad, si bien tiene una estructura equivalente a otros discursos populistas en el mundo, centrado en el significante pueblo y, a partir de ahí, divide la sociedad en dos campos antagónicos que se oponen moralmente, es sobredeterminado por ciertos elementos propios del discurso político de los pobladores que ya han sido identificados por la literatura especializada. Tanto el sufrimiento compartido como la dignidad operan como restricciones discursivas que limitan la flexibilidad del significante pueblo.

\section{Conclusiones}

En el presente artículo, hemos querido demostrar cómo el discurso político radical, identificado en manifestaciones anteriores en el movimiento de pobladores, es interpretado y comunicado actualmente por el Partido Igualdad. Esto no quiere decir, por una parte, que todos los pobladores adhieran a este discurso, ni, por otra, que todos los pobladores radicales políticamente se identifiquen con el Partido. Lo que hemos mostrado es una variante posible del discurso político radical que se articula con los discursos cotidianos de los pobladores y que, por lo mismo, está presente en otras organizaciones que no están contenidas orgánicamente en el partido. Asimismo, la forma del diagnóstico de Igualdad acerca de la sociedad chilena puede encontrarse en "críticas ordinarias" 90 realizadas por los pobladores a propósito de la segregación socioespacial que los afecta, sin que, por ello, adscriban a un discurso político en específico.

\footnotetext{
88 Gonzalo, MPL.

${ }^{89}$ Humberto, MPL.

90 Luc Boltanski, De la critique. Précis de sociologie de l'émancipation, Paris, Gallimard, 2009.
} 
Tal como hemos señalado, la estructura del discurso político de Igualdad coincide con la definición que realiza la literatura contemporánea acerca del populismo, en el sentido de que posiciona al pueblo como una voluntad colectiva global y, a partir de ello, estructura el campo político de forma antagónica, traduciendo dicho antagonismo en clave moral. Sin embargo, como vimos, este significante tiene una extensión limitada de acuerdo a las formas en que se articula con el discurso político de los pobladores. De esta forma, a la pregunta ¿qué es el pueblo?, Igualdad responde: son todos aquellos que sufren las consecuencias del sistema capitalista y que, pese a ello, son capaces de levantarse y exigir colectivamente una vida digna.

Esta respuesta que da el Partido Igualdad le permite articular una cadena de demandas equivalentes y apelar a una multiplicidad de subjetividades que exceden el espacio de los pobladores, sin embargo, le impone restricciones respecto a la posibilidad de articularse políticamente con actores provenientes de otras clases sociales. La reciente incorporación de Igualdad al Frente Amplio desafía los límites discursivos que hemos identificado en este artículo y, en este sentido, puede marcar una apertura de su estructura y una resignificación del significante pueblo. Hasta qué punto un discurso político populista como el que moviliza Igualdad puede articularse con otros discursos de izquierda socialista o socialdemócrata era un desafío en décadas pasadas y lo sigue siendo en la actualidad. Esperamos que con este trabajo podamos orientar futuras investigaciones en esta dirección.

\section{Referencias bibliográficas}

\section{Libros y artículos}

Angelcos, Nicolás y María Luisa Méndez, "Struggles against territorial disqualification. Mobilization for dignified housing and defense of heritage in Santiago", Latin American Perspectives, vol. 44, n³, 2017, pp.100-112.

Angelcos, Nicolás y Miguel Pérez, "De la "Desaparición" a la Reemergencia: Continuidades y Rupturas del Movimiento de Pobladores en Chile", Latin American Research Review, vol. 52, n¹, 2017, pp. 94-109.

Angelcos, Nicolás, "Movimiento de pobladores. Lucha social y política en el Chile contemporáneo", Revista Educação em perspectiva, vol. 7, n², 2016, pp. 324-345.

Araujo, Kathya, Habitar lo social: usos y abusos en la vida cotidiana en el Chile actual, Santiago de Chile, LOM, 2009.

Arriagada, Evelyn, "Clientelismo político y participación local. El rol de los dirigentes sociales en la articulación entre autoridades y ciudadanos en Santiago de Chile", Revista Polis, n³6, 2013, pp. 15-38.

Auyero, Javier, La politica de los pobres, Buenos Aires, Manantial, 2012.

Auyero, Javier, Pacientes del Estado, Buenos Aires, Eudeba, 2013. 
Nicolás Angelcos, Claudia Jordana, Cristóbal Sandoval, Sólo en el pueblo confiamos: la estructura moral del discurso político radical de los pobladores en el Partido Igualdad, Izquierdas, 46, mayo 2019:22-46

Baño, Rodrigo, Lo social y lo político. Un dilema clave del movimiento popular, Santiago de Chile, FLACSO, 1984.

Barozet, Emmanuelle, "Elementos explicativos de la votación de los sectores populares en Iquique: lógica y eficiencia de las redes clientelares", Política, n43, 2004, pp. 205-251.

Barozet, Emmanuelle, “La compra de votos en Chile o cómo se coopta a los sectores populares", Contribuciones científicas y tecnológicas, pp.10-15.

Boltanski, Luc, De la critique. Précis de sociologie de l'émancipation, Paris, Gallimard, 2009.

Bruey, Alison, "Limitless land and the redefinition of rights: popular mobilisation and the limits of neoliberalism in Chile, 1973-1985", Journal of Latin American Studies, vol. 44, 2012, pp.523-552.

Campero, Guillermo, Entre la sobrevivencia y la acción política: las organizaciones de pobladores en Santiago, Santiago de Chile, Estudios ILET, 1987.

Candina, Azun, "Seguridad ciudadana y sociedad en Chile contemporáneo. Los delincuentes, las políticas y los sentidos de una sociedad", Revista de estudios históricos, vol. 2, nº 1, agosto 2005.

Castells, Manuel, "Movimientos de pobladores y lucha de clases en Chile", Revista EURE - Revista De Estudios Urbano Regionales, vol. 3, n7, 1973, pp.9-35.

Cofré, Boris, "El movimiento de pobladores en el Gran Santiago: las tomas de sitios y organizaciones en los campamentos. 1970-1973", Tiempo histórico, n², 2011, pp.133-157.

Cortés, Alexis, "El movimiento de pobladores chilenos y la población La Victoria: ejemplaridad, movimientos sociales y el derecho a la ciudad". Revista EURE, vol.40, n¹19, 2014, pp.239-260.

Cortes, Alexis y Alejandro Pelfini, “El populismo en chile: ¿tan lejos o tan cerca?", Izquierdas, n³2, marzo 2017, pp. 58-78.

Cury, Marcia, El protagonismo popular chileno. Experiencias de clase y movimientos sociales en la construcción del socialismo (1964-1973), Santiago, LOM, 2018.

De Cleen, Benjamin, Glynos, Jason y Mondon, Aurelien, "Critical research on populism: nine rules of engagement", Organization, Online first, abril 2018, pp. 1-13. http://journals.sagepub.com/doi/10.1177/1350508418768053.

Doran, Marie-Christine, "La palabra soberana: los pobladores chilenos frente a la política", Versión, n'10, octubre 2000, pp. 287-329.

Dubet, François, "Las conductas marginales de los jóvenes pobladores", Proposiciones, Marginalidad, movimientos sociales y democracia, $\mathrm{n}^{\circ} 14$, Santiago de Chile, agosto 1987, pp. 94-100.

Dubet, François, Eugenio Tironi, Vicente Espinoza y Eduardo Valenzuela, Pobladores. Luchas sociales y democracia en Chile, Santiago de Chile, Ediciones Universidad Alberto Hurtado, 2016.

Espinoza, Vicente, Para una historia de los pobres de la ciudad, Santiago, Ediciones Sur, 1988. 
Espinoza, Vicente, "Historia social de la acción colectiva urbana: los pobladores de Santiago, 1957-1987", Revista EURE, vol. 24, n72, 1998, pp.7184.

Forst, Rainer, Justificación y crítica, Buenos Aires, Katz, 2015.

Freeden, Michael, Ideologies and Political Theory: A Conceptual Approach, Oxford, Oxford University Press, 1996.

Garcés, Mario, Tomando su sitio: el movimiento de pobladores de Santiago, 19571970, Santiago, LOM, 2002.

González de la Rocha, Mercedes, Janice Perlman, Helen Safa, Elizabeth Jelin, Bryan R. Roberts y Peter M., "Ward, From the Marginality of the 1960s to the "New Poverty" of today: A LARR Research Forum", Latin Research Review, vol. 31, n¹, 2004, pp.183-203.

Han, Clara, Life in debt: Times of Care and Violence in Neoliberal Chile, Berkeley, University California Press, 2012.

Hardy, Clarisa, Organizarse para vivir. Pobreza urbana y organización popular, Santiago de Chile, PET, 1987.

Honneth, Axel, La lutte pour la reconnaissance: grammaire morale des conflits sociaux, Paris, Cerf, 2010.

Iglesias, Mónica, Rompiendo el cerco: El movimiento de pobladores contra la dictadura, Santiago, Radio Universidad de Chile, 2011.

Mónica Iglesias, "La construcción teórica de los movimientos sociales en Chile: el movimiento de pobladores, entre la sociología y la historia social", Revista Austral de Ciencias Sociales, n³0, 2016, pp.145-160.

Koppelman, Carter M., “Deepening Demobilization: The State's Transformation of Civil Society in the Poblaciones of Santiago, Chile", Latin American Perspectives, vol. 44, n³, 2017, pp. 46 - 63.

Laclau, Ernesto, "Lógicas de la Construcción Política e Identidades Populares", José Luis Coraggio y Jean-Louis Laville (coord.), Reinventar la Izquierda en el Siglo XXI: Hacia un Dialogo Norte-Sur, Los Polvorines, Universidad Nacional de General Sarmiento, 2014.

Laclau, Ernesto, Emancipation(s), London, Verso, 1996.

Laclau, Ernesto, La Razón Populista, Buenos Aires, FCE, 2005.

Lewis, Oscar, Los hijos de Sánchez, México, Fondo de Cultura Económica, [1961] 2012.

Loyola, Manuel, Los pobladores de Santiago, 1952-1964, Santiago, Ediciones Universidad Católica Raúl Silva Henríquez, 2006.

Madrid, Sebastián, “¿Políticos de ayer, apáticos de hoy? Generaciones, juventud y política en Chile", Claudia Fuentes y Andrés Villar, Voto ciudadano. Debate sobre la inscripción electoral, Santiago de Chile, FLACSO, pp. 45-84.

Martínez, Javier y Margarita Palacios, Informe sobre la decencia. La diferenciación estamental, Santiago de Chile, Ediciones Sur, 1996.

Mudde, Cas, "The Populist Zeitgeist", Government and Opposition, vol. 39, n4, 2004, pp. 541-563. 
Murphy, Edward, For a proper home: Housing Rights in the Margins of Urban Chile, 1960-2010, Pittsburgh, University of Pittsburgh Press, 2015.

Oxhorn, Philip, "The popular response to an authoritarian regime: shantytown organizations since the military coup", Latin American Perspectives, vol. 18, n¹, invierno 1991, pp. 66-91.

Oxhorn, Philip, "Where did all the protesters go?: Popular mobilization and the transition to democraty in Chile", Latin American Perspectives, vol. 21, n'3, verano 1994, pp. 49-68.

Özler, Ş. İlgü, “The Concertacion and Homelessness in Chile: Market-based Housing Policies and Limited Popular Participation", Latin American Perspectives, vol. 39, n4, 2012, pp. $53-70$.

Paley, Julia, Marketing democracy: Power and Social Movements in PostDictatorship Chile, Berkeley, University California Press, 2001.

Pérez, Ani $\square$ bal C., ¿UDI popular? Los campamentos y el respaldo electoralpopular de derecha. El caso de Virginia Reginato en Vin $\square$ a del Mar (20082013), Izquierdas, $\mathrm{n}^{\circ}$ 21, octubre 2014, pp. 1-30.

Pérez, Miguel, "A new poblador is being born". Housing Struggles in a Gentrified Area of Santiago", Latin American Perspectives, vol. 44, n³, 2016, pp. 28-45.

Razeto, Luis, Economía popular de solidaridad. Identidad y proyecto en una visión integradora, Santiago de Chile, PET, 1986.

Riveros, Claudio, "El proceso populista: un aporte teórico al debate del fenómeno", Izquierdas, n³8, febrero 2018, pp. 61-88.

Salazar, Gabriel, La violencia política popular en las "Grandes Alamedas". La violencia en Chile 1947-1987 (Una perspectiva histórico popular), Santiago, LOM, 1987.

Taylor, Charles, El multiculturalismo y la "política del reconocimiento, México, D.F., Fondo de Cultura Económica, 1993.

Tironi, Eugenio, "El fantasma de los pobladores", Estudios sociológicos, vol.4, no12, sept.-dic, 1986, pp. 391-397

Touraine, Alain, "La centralidad de los marginales", Proposiciones, Marginalidad, movimientos sociales y democracia, vol. 14, Santiago de Chile, 1987, pp. 214-224.

Vekemans, Roger y Ramón Venegas, "Marginalidad y promoción popular", Revista Mensaje, 149, 1966.

\section{Fuentes periódicas}

Revista Voces por la Igualdad, n¹, agosto 2010

Revista Voces por la Igualdad, $\mathrm{n}^{\circ} 4$, agosto 2010

Revista Voces por la Igualdad, n³, noviembre 2012.

Revista Voces por la Igualdad, $\mathrm{n}^{\circ}$, noviembre 2012.

Revista Voces por la Igualdad, n4, diciembre 2012.

Revista Voces por la Igualdad, n5, marzo 2013. 
Revista Voces por la Igualdad, n 9, octubre 2013

Diario Voces de la Igualdad, 2010-2013

\section{Sitio Web}

https:/ / partidoigualdad.cl

http:/ / andha.cl

Entrevistas

Denis, militante Igualdad.

Igor, militante Igualdad.

Nuria, militante Igualdad.

Gonzalo, militante Igualdad.

Humberto, militante Igualdad.

\section{Discursos}

Aylwin, Discurso 21 de mayo, 1990. 